\title{
Échange avec Montserrat Sans sur la dimension judiciaire de la question des disparus en Espagne
}

\section{Montserrat Sans}

\section{(2) OpenEdition \\ 12 Journals}

Édition électronique

URL : http://journals.openedition.org/conflits/14233

DOI : $10.4000 /$ conflits. 14233

ISSN : $1777-5345$

Éditeur :

CCLS - Centre d'études sur les conflits lilberté et sécurité, L'Harmattan

Édition imprimée

Date de publication : 20 décembre 2008

ISBN : 1157-966 X

ISSN : 1157-996X

\section{Référence électronique}

Montserrat Sans, «Échange avec Montserrat Sans sur la dimension judiciaire de la question des disparus en Espagne », Cultures \& Conflits [En ligne], 72 I hiver 2008, mis en ligne le 08 janvier 2009, consulté le 30 mars 2021. URL : http://journals.openedition.org/conflits/14233 ; DOI : https://doi.org/ $10.4000 /$ conflits. 14233

Ce document a été généré automatiquement le 30 mars 2021.

Creative Commons License 


\title{
Échange avec Montserrat Sans sur la dimension judiciaire de la question des disparus en Espagne
}

\author{
Montserrat Sans
}

C\&C : En 2002, vous avez présenté un texte devant le groupe de travail de l'ONU sur les disparitions forcées de personnes. Quel était l'enjeu d'une éventuelle intervention de l'ONU dans ce cas précis, en relation au cas des disparitions perpétrées en Espagne?

Montserrat Sans : Ce n'est qu'en 2001 que les nouvelles générations, nées après la transition espagnole, prennent conscience de l'ampleur des atrocités de la guerre civile (1936-1939), des milliers de corps anonymes sans sépulture, de la chape de plomb sur la répression franquiste. Le silence sur l'horreur de cette guerre a continué à peser dans le quotidien de la transition à la démocratie (1976-1978). Les manuels scolaires ne parlaient ni des milliers de fusillés, ni des dizaines de camps de prisonniers politiques, mais insistaient seulement sur les aspects militaires des grandes batailles. Avec l'irruption sur la scène publique du journaliste Emilio Silva recherchant son grand-père fusillé par les troupes franquistes, et retrouvant à ses côtés les treize corps des conseillers municipaux du Bierzo, la presse espagnole a commencé à se faire l'écho d'un phénomène jusqu'alors inavouable : des milliers de disparus jonchent les terres d'Espagne! Comment justifier que, après pratiquement trois décennies, la démocratie n'ait pas eu un geste institutionnel à l'égard des familles de ces instituteurs, travailleurs agricoles, ouvriers "paseados ${ }^{1}$ " par les troupes du général Franco ? L'action devant le Groupe de travail sur les disparitions forcées de l'ONU se situe dans un double contexte national : le second mandat du président Aznar, chantre de la droite catholico- nationaliste qui établit que la démocratie est née par génération spontanée au moment de la transition espagnole, niant donc toute légitimité à la République espagnole; et le verrouillage systématique du pouvoir judiciaire, à savoir :

- L'impossibilité d'obtenir un mécanisme institutionnel donnant aux familles des victimes antifranquistes la possibilité de récupérer leurs corps (droit à exhumer) ou 
d'obtenir des informations sur les circonstances et le lieu de leur mort (identification des restes, transfert des corps vers des cimetières municipaux, etc.).

- L'attitude des juges déboutant à coups de loi d'amnistie (voir ci-après) toutes les demandes des familles clamant leur droit à donner une digne sépulture aux restes d'un père, allant même, dans certains cas, à nier l'existence même de la victime par manque de preuves.

- L'urgence de trouver une solution pour des dizaines de veuves dont le dernier désir était de reposer auprès de leur mari.

Face à ce blindage légal et judiciaire, l'internationalisation du phénomène, l'appel à l'aide de l'ONU étaient incontournables pour mettre en évidence le manque de protection juridique des familles de disparus, le maintien du deuil suspendu qu'implique toute disparition, et l'impunité gérée par les autorités en place. Toutes ces conditions sont conformes à ce que la communauté internationale qualifie comme un affront à l'humanité.

C\&C : La loi d'amnistie de 1977 est-elle donc encore en vigueur? Et comment coexiste-t-elle avec la législation internationale?

M. S.: La loi d'amnistie de 1977 est une colonne fondamentale de la transition espagnole. Elle est non seulement en vigueur, inaltérée malgré son entorse aux conventions en matière de droits de l'Homme ratifiées par l'Espagne, mais son article 2 continue d'être invoqué aujourd'hui par la plupart des tribunaux civils ou militaires espagnols pour débouter les demandes de révision judiciaire des conseils de guerre, des condamnations à mort ou des demandes d'enquête sur une disparition ${ }^{2}$.

Il est important de rappeler tout d'abord que la gauche espagnole fut le fer de lance qui réclama depuis les années 1960 l'amnistie politique afin de libérer les prisonniers politiques et permettre le retour des exilés, l'élimination des mentions politiques sur les casiers judiciaires. « Aministía y Libertad » criaient les manifestants dans les rues. La loi d'amnistie a eu pour effet la sortie de prison de centaines de prisonniers d'opinion à l'hiver 1977. Elle instaurait simultanément l'impunité de tous les crimes commis par les militaires, gardes civils ou groupes de choc franquistes et le maintien des tortionnaires dans les institutions. Aujourd'hui, le maintien de ceux-ci n'est même pas en discussion à gauche.

Son abrogation supposerait la rupture de la logique réformiste de la transition. En d'autres termes, la loi d'amnistie a été systématiquement préservée sous prétexte que son abrogation introduirait une insécurité juridique imparable. Elle est en fait la clef de voûte du débat sur la construction de la mémoire historique de l'Espagne, sur l'impossibilité de tourner la page eu égard à ce qui a été négocié en 1976, sur l'impossibilité de faire justice, et ouvre la discussion sur le régime constitutionnel et, donc, le maintien de la monarchie.

Ensuite, il faut savoir que dans l'histoire de l'Espagne, les luttes sectaires (entre les antifranquistes) continuèrent durant l'exil. Ces querelles politiques n'ont pas laissé de place aux thèses des droits de l'Homme qui commencent à s'imposer à la fin des années 1960. Le président de l'Institut des droits de l'Homme et de la Commission internationale des juristes d'Espagne - désigné par Felipe Gonzalez - était un ancien ministre de Franco, Conseiller national du Movimiento ${ }^{3}$ ! 
A la différence de l'Amérique latine, où les défenseurs des droits de l'Homme (associations des familles de victimes de crimes commis sous les diverses dictatures) ont réussi à créer des concepts et des mécanismes de protection pendant les dictatures, qui sont vite devenus les bases incontournables du système international de protection des droits de l'Homme, dans l'Espagne franquiste, ce sont les avocats du droit du travail qui prennent la défense des antifranquistes, sur la base de la légalité établie par la dictature. Cela peut s'expliquer tant par le fait que les républicains ont perdu tant la guerre que leur légitimité face à la communauté internationale (Franco a été reconnu très vite après la Seconde Guerre mondiale) et que la dictature a duré quarante ans. La transition s'est donc engagée loin des débats sur les droits de l'Homme parce que les propres partis (de droite ou de gauche) n'ont pas inclus cet instrument dans leur stratégie. Il fallait (pour tous) oublier la guerre et les exactions, donc tourner la page.

\section{NOTES}

1. «Promenés » selon l'euphémisme en vigueur. Il faut lire : tués et enterrés dans des fosses communes.

2. «Dans tous les cas sont compris dans l'amnistie : [...]

(e) Les délits et les fautes que pourraient commettre les autorités, fonctionnaires et agents de l'ordre public, à l'occasion de la recherche et de la poursuite d'actes prévus dans cette Loi.

(f) Les délits commis par les fonctionnaires et les agents de l'ordre public contre l'exercice des droits des personnes ». Art. 2, Loi d'amnistie de 1977 (cité par M. Sans).

3. «Movimiento nacional». Nom donné par les franquistes au système politique qu'ils instaurent.

\section{AUTEUR}

\section{MONTSERRAT SANS}

Montserrat Sans est juriste, ex-fonctionnaire des Nations unies, actuellement membre de l'Association pour la récupération de la mémoire historique (ARMH). 